\title{
Rectal biopsy in the diagnosis of systemic vasculitis
}

\author{
CR TRIBE, DGI SCOTT, PA BACON \\ From Southmead Hospital, Bristol and the Royal National Hospital for Rheumatic Diseases, Bath
}

SUMMARY Vasculitis has been seen in rectal biopsies from 22 patients over a six year period. The most common finding was a necrotising vasculitis of small arteries, indistinguishable from that seen in polyarteritis nodosa (PAN). Sub-acute, chronic ("burnt out") and leucocytoclastic changes were also seen. Sixteen patients had vasculitis complicating rheumatoid arthritis (RA), 3 PAN and 3 overlap syndromes. Patients with RA and rectal vasculitis had a higher mortality, and a greater incidence of neuropathy than those with negative biopsies. An adequate biopsy is positive in $40 \%$ of patients with clinical vasculitis and RA but was only positive in one of a control series of 46 RA patients with no clinical vasculitis. Rectal biopsy in experienced hands is a safe, and repeatable procedure. It is useful as a "blind" biopsy site in the diagnosis of systemic vasculitis, especially that complicating RA. It can also be used for serial studies of the evolution of vasculitis. Serial sections of the entire biopsy may be required to reveal the vasculitis which is often focal in nature.

Since the original report by Gafni and Sohar ${ }^{1}$ rectal biopsy is now recognised as the standard method to establish a tissue diagnosis in patients with generalised amyloidosis. It has also been used to establish the incidence of amyloidosis in rheumatoid arthritis ${ }^{2}$ and repeat biopsies have been used to follow the natural history and assess the effect of therapeutic agents on this disease. ${ }^{3}$

Whilst examining rectal biopsies from patients with RA in order to diagnose amyloidosis, in several cases a necrotising vasculitis was found in the submucosal vessels. There are only two previous reports 45 of vasculitis in this biopsy site; both restricted to small numbers of patients. We now perform rectal biopsies on all cases of suspected systemic vasculitis.

\section{Material and methods}

During the period 1974-80 rectal biopsies from approximately 120 patients with suspected vasculitis were examined and histological evidence of vasculitis was found in 22 patients. Three quarters of the biopsies were taken from patients with RA and the remainder from patients with a variety of connective tissue diseases such as PAN, systemic lupus erythematosus, Wegner's granulomatosis etc.

Rectal biopsies from two groups of patients with RA and no clinical signs of vasculitis were also examined to assess the accuracy of this biopsy site in the diagnosis of systemic vasculitis. These were 31 patients with long standing RA and 15 patients with active rheumatoid synovitis.

The rectal biopsies were obtained by ordinary tissue biopsy forceps through a proctoscope from the posterior wall of the rectum usually $5-10 \mathrm{~cm}$ above the anus. By twisting the biopsy forceps to remove the tissue sample local haemorrhage occurred less frequently than by pulling the sample free from the rectal wall. Deeper rectal biopsies were needed for the diagnosis of vasculitis than those taken for the diagnosis of amyloidosis in order to include groups of small submucosal arteries.

\section{HISTOLOGY}

The biopsies were routinely fixed in buffered formalin, paraffin-embedded and sectioned at $4 \mu \mathrm{m}$. Step sections were taken and stained with haematoxylin and eosin. At one level crystal violet and Sirius Red stains were used to exclude amyloidosis, and elastic stains were used to assist the diagnosis of "burnt out" vasculitis.

\section{Results}

During the seven years, $1974-80$, the diagnosis of vasculitis has been made in rectal biopsies from 22 patients.

The clinical diagnosis on these patients was as follows:

Rheumatoid vasculitis 16 cases

Polyarteritis nodosa 3 cases

Overlap syndromes 3 cases 
PATHOLOGY

It was found to be essential to take step sections throughout the biopsies as vasculitis is a peculiarly focal disease and in several cases no vasculitis could be found in the first sections examined, with florid necrotising vasculitis only revealed in the deeper sections. In 20 of the 22 cases the vasculitis only involved arteries and the histological types fell into four groups:

Acute necrotising vasculitis

Sub-acute vasculitis

15 cases

Chronic ("burnt out") vasculitis 1 case

Leucocytoclastic vasculitis (a) Acute necrotising vasculitis-15 cases

In these patients small submucosal arteries showed the classical features of necrotising vasculitis with fibrinoid necrosis of the intima and extensive transmural infiltration with inflammatory cells. In $\stackrel{\overrightarrow{9}}{\vec{s}}$ the most acute cases leucocytoclasis and neutrophils were present as well as mononuclear cells. Eosinophils were also sometimes seen but never in large $\frac{\bar{c}}{\sigma}$ numbers (Figs. 1a and b).

(b) Sub-acute vasculitis-5 cases

In these patients the inflammatory reaction was $\overrightarrow{0}$ much less than in (a) with only lymphocytes present.

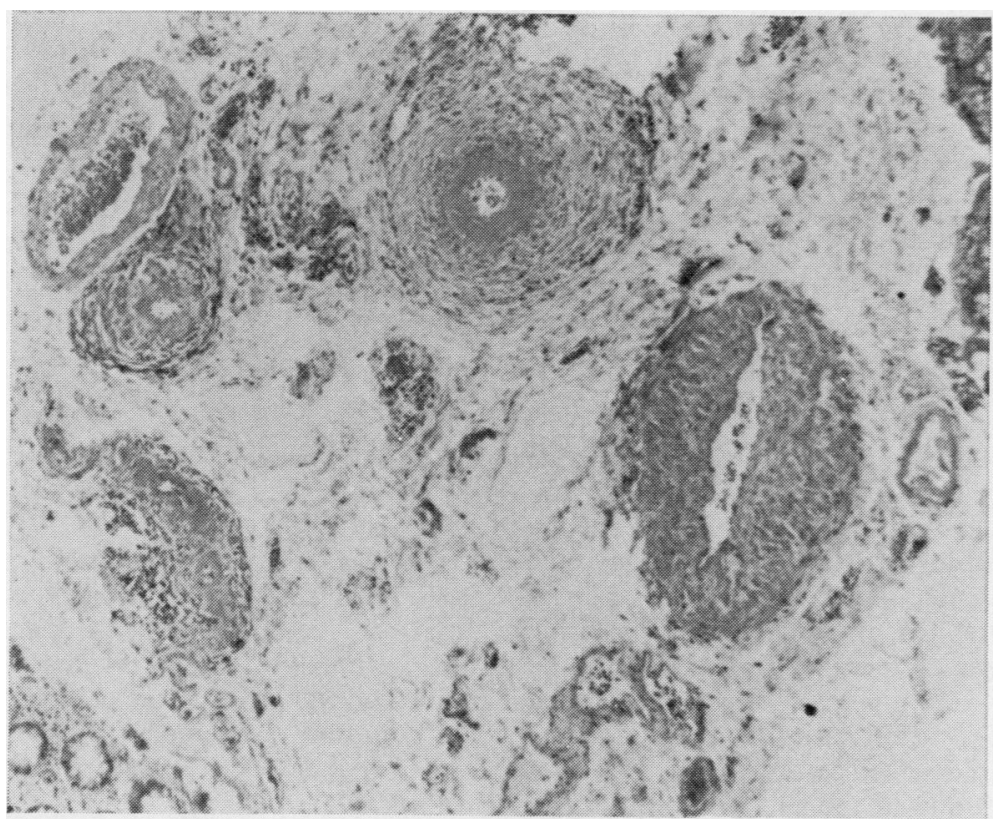

Fig. 1 Photomicrographs from the rectal biopsy of patient $A B$ (female). (a) Low power view showing acute necrotising vasculitis affecting muscular arteries of all calibre throughout the submucosa. Note the absence of inflammatory changes in veins and capillaries. Haematoxylin and eosin $\times 120$.

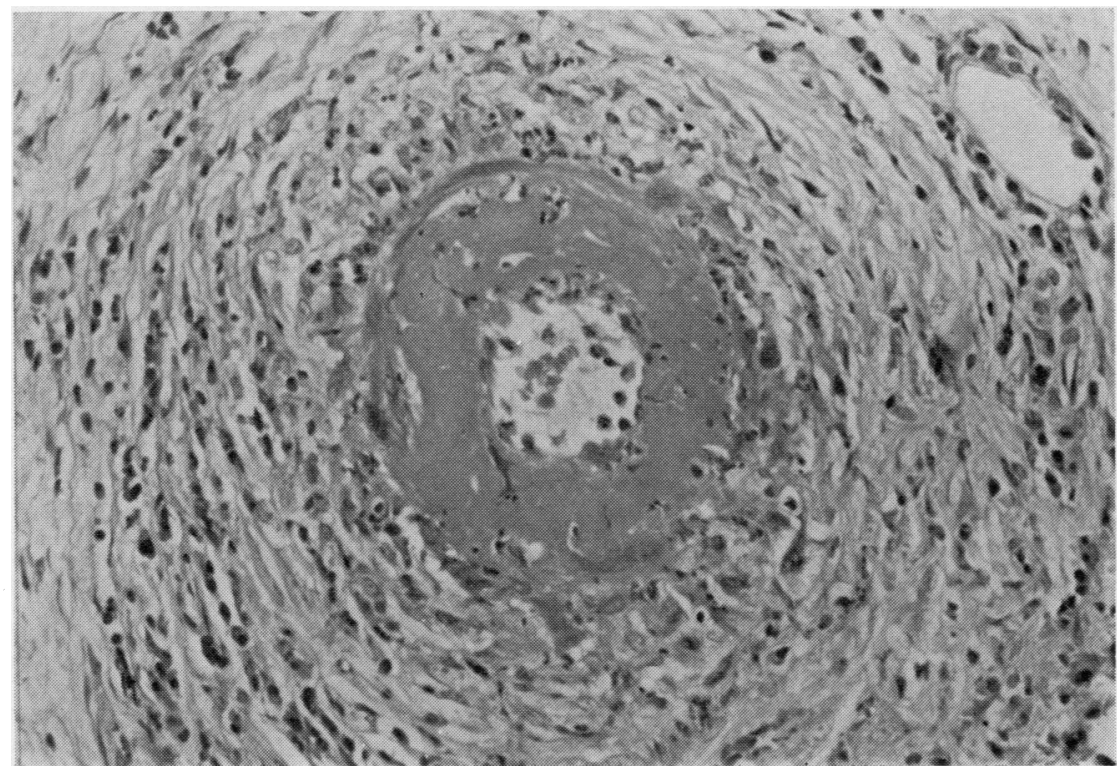

(b) High power view showing "classical" necrotising arteritis with extensive fibrinoid necrosis of the intima and infiltration of all coats by acute and chronic inflammatory cells with leucocytoclasis. Haematoxylin and eosin $\times 500$. 
Sometimes fibrinoid necrosis of the intima was still apparent (Figs. 2a and b). In one patient ( $\mathrm{RH})$ this low grade vasculitis appeared to involve only veins.

(c) Chronic ("burnt out") vasculitis-1 case

The evidence for vasculitis in this patient (GR) was confined to distortion and rupture of the internal elastic lamina.

In a further single patient (EL) four serial biopsies were studied over a period of ten months. These showed the natural history and "healing" of the vasculitis which was of the acute necrotising variety in the first two biopsies, sub-acute in the third and "burnt out" in the last biopsy. In the latter another interesting histological feature was the presence of large haemosiderin granules in the wall of the vessel. This case illustrates that the histological changes described in (a), (b) and (c) are different stages of the same disease process.

Extensive destruction of the elastic fibres in the arterial walls occurred in the acute, sub-acute and chronic types (Figs. 3a, b, c, d).

(d) Leucocytoclastic vasculitis-1 case In one patient $(\mathrm{CJ})$ the only evidence of vasculitis was a leucocytoclastic reaction with fibrin in the lumen of the submucosal and mucosal capillaries. This patient with RA developed a purpuric rash, and skin biopsy showed similar leucocytoclastic changes.

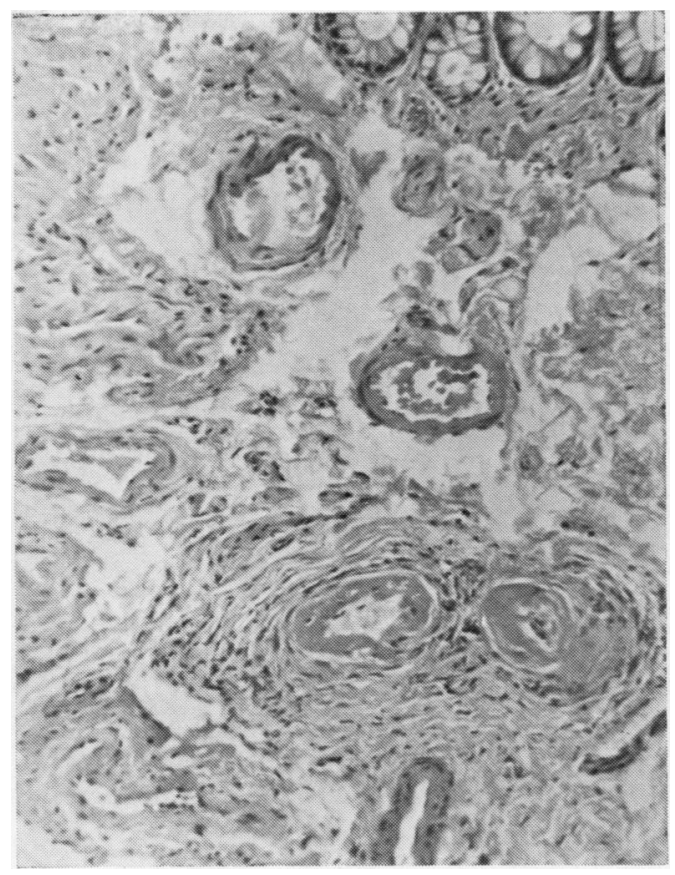

Fig. 2 Photomicrographs from the rectal biopsy of a patient with mixed connective tissue disease (see overlap syndromes). (a) Low power view showing sub-acute vasculitis involving only two small submucosal arteries. Haematoxylin and eosin $\times 250$.

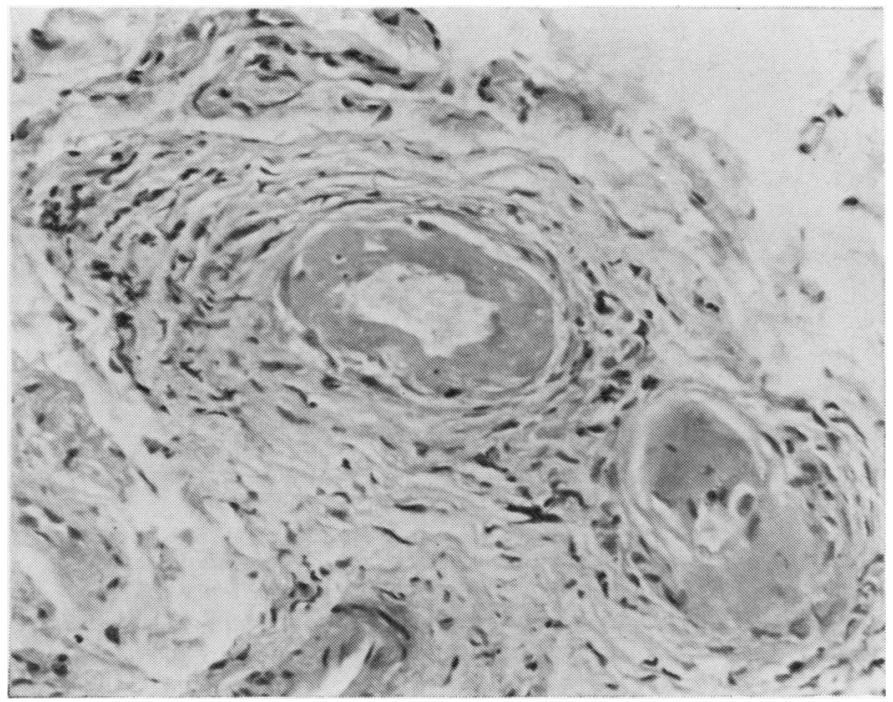

(b) High power view showing fibrinoid necrosis of the intima but only a mild lymphocytic infiltrate without leucocytoclasis. Haematoxylin and eosin $\times 500$. 

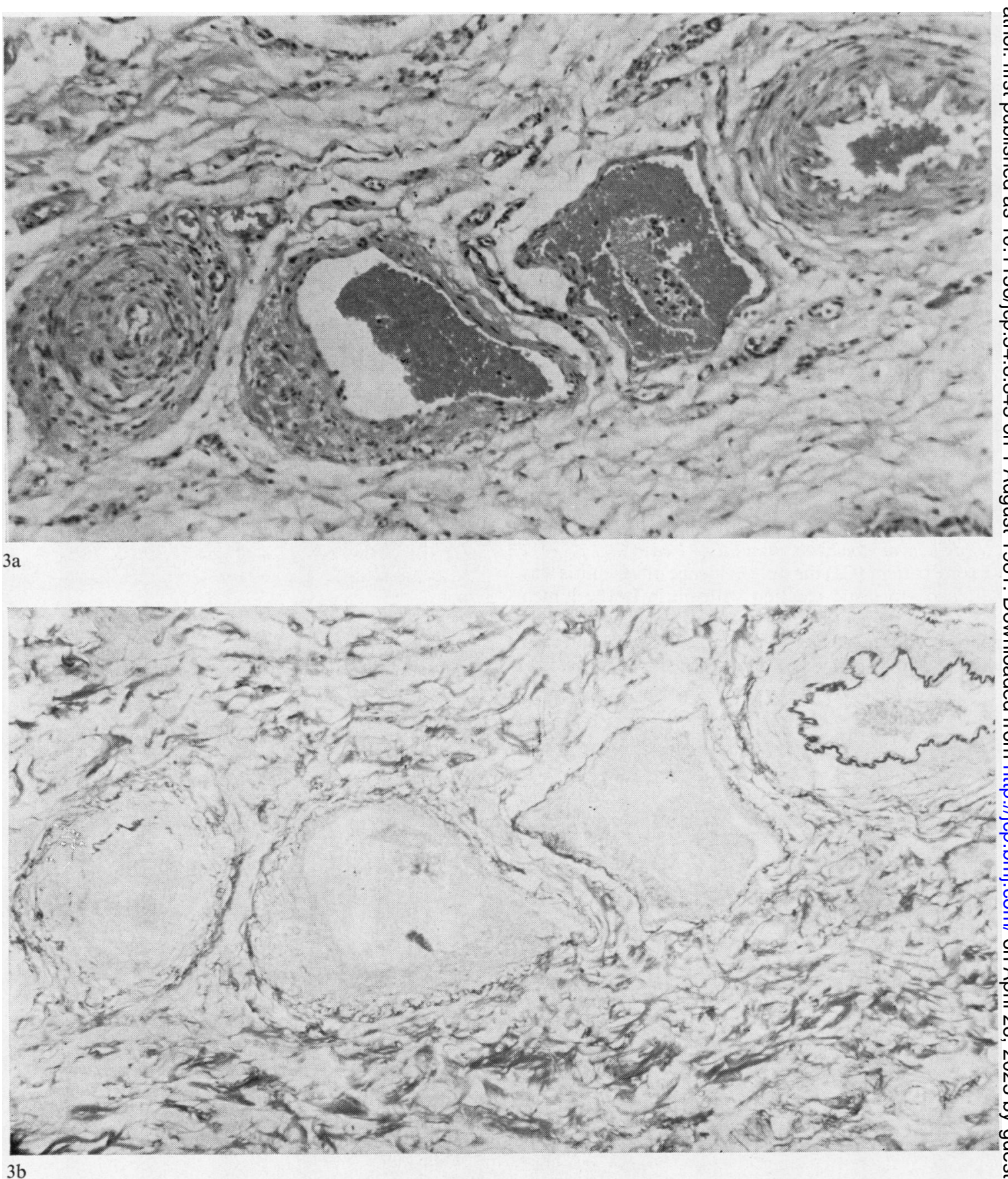

$3 \mathrm{~b}$

Fig. 3 Photomicrographs from a follow-up rectal biopsy of patients (EY). (a) Low power view of four submucosal vessels showing sub-acute vasculitis in the artery (left) without fibrinoid necrosis. Note the complete absence of inflammation in the artery (right) and two central veins. Haematoxylin and eosin $\times 250$. (b) Elastic stain of 3a showing disruption of the internal elastic lamina of the affected artery in contrast to the normal elastic architecture of the other vessels. Miller's stain $\times 250$. 


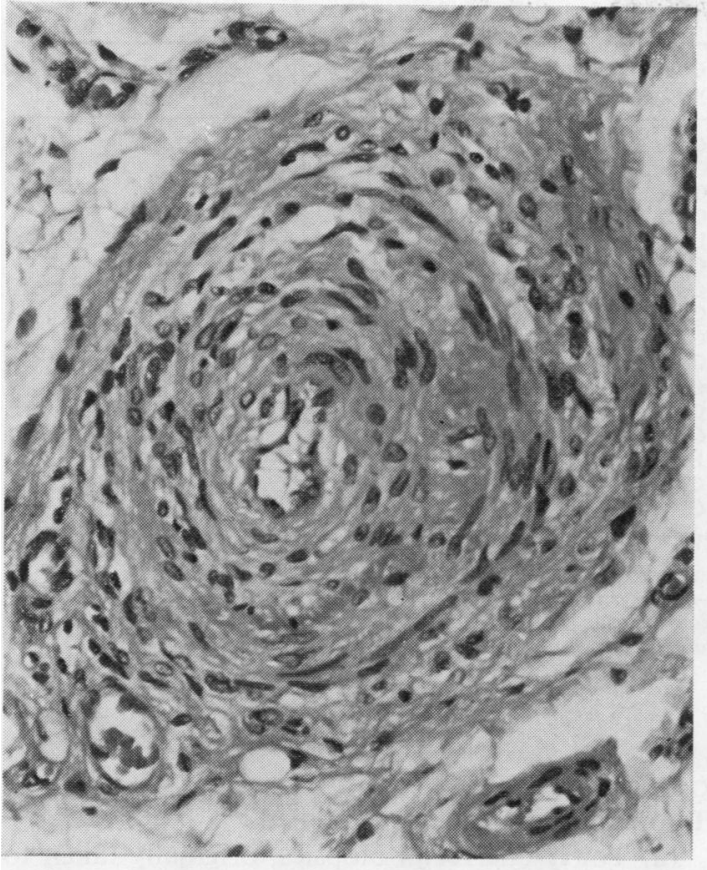

$3 c$

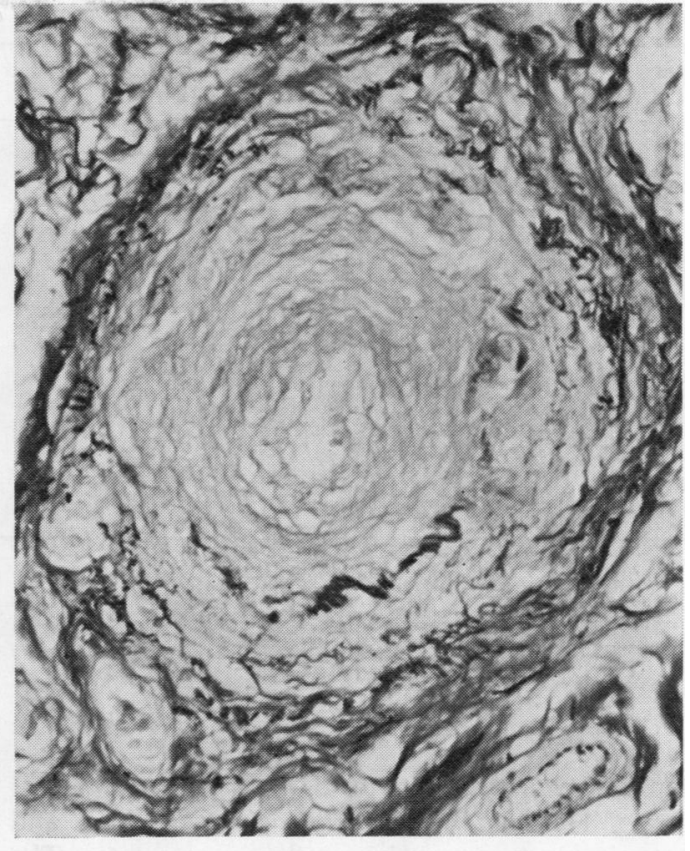

$3 \mathrm{~d}$

Fig. 3(c) High power of the affected artery in 3a. Haematoxylin and eosin $\times 500 .($ d) Elastic stain of 3c. Miller's stain $\times 500$.

\section{CLINICAL FEATURES}

(a) Rheumatoid vasculitis-16 cases

The clinical features of the 16 patients with RA are summarised in the Table. There were eight men and eight women, with an average age of $62 \mathrm{yr}$ (38-73) and a mean duration of the arthritis of $11 \mathrm{yr}(6$ months-30 yr). 13 were seropositive at the time of biopsy and 12 had typical rheumatoid nodules.

The commonest clinical features of vasculitis were cutaneous and included digital infarction and deep cutaneous ulceration. Other features included peripheral neuropathy, scleritis, pericarditis, fibrosing alveolitis and haematuria.

Six of these 16 patients have died. This represents two thirds of all patients in this group who have been followed for more than two years. Three of the six who died had a mononeuritis multiplex, but no other clinical features of vasculitis were prominent in this group. The cause of death is not known in all cases but 2 patients had evidence of active vasculitis at necropsy.

The majority of our biopsies were taken from patients included in a large clinical survey of 50 cases of systemic rheumatoid vasculitis reported in detail elsewhere. ${ }^{6}$ Thirty-five of these patients had rectal biopsies and $12(34 \%)$ showed vasculitis. Patients with positive rectal biopsies had a higher incidence of neuropathy, circulating immune complexes and mortality, than those with negative rectal biopsies. Eighteen of the 23 negative biopsies were personally reviewed (CRT) and five were considered inadequate for the diagnosis of vasculitis due to the absence of any muscular vessels. Thus $40 \%$ of adequate biopsies were positive. This suggests that with deeper biopsies the incidence of positive rectal biopsies could be increased.

\section{(b) Polyarteritis nodosa-3 cases}

Three patients had clinical features strongly suggestive of polyarteritis nodosa. The first, a 57-year-old man presented with thrombophlebitis, a tender testis, proteinuria, eosinophilia and an ESR (erythrocyte sedimentation rate) of $137 \mathrm{~mm} / \mathrm{h}$. Rectal biopsy showed a classical necrotising arteritis. He was treated with corticosteroids and azathioprine and at follow-up six years later he has well-controlled hypertension with only a mild impairment of renal function. The second, a 75-year-old man, presented with myalgia, sensory neuropathy, and fibrosing alveolitis. A muscle biopsy confirmed a necrotising arteritis and a subsequent rectal biopsy also showed 
Summary of clinical details in 16 patients with rheumatoid arthritis with evidence of vasculitis at rectal biopsy

\begin{tabular}{|c|c|c|c|c|c|c|c|c|}
\hline Patient & Sex & Age & Biopsy date & $\begin{array}{l}\text { Duration of } \\
R A(y r)\end{array}$ & Nodules & $\begin{array}{l}\text { Clinical features of } \\
\text { vasculitis }\end{array}$ & Outcome after biopsy & $\begin{array}{l}\text { **Histological type of } \\
\text { vasculitis }\end{array}$ \\
\hline AB & $\mathbf{M}$ & 56 & 1974 & 6 & + & $\mathbf{C}, \mathbf{S}, \mathbf{N}$ & Died after 18 months & Ac Nec \\
\hline FO & $\mathbf{M}$ & 73 & 1975 & 14 & + & $\mathrm{C}, \mathrm{N}$ & Died after 14 months & Ac Nec \\
\hline $\mathbf{A S}$ & $\mathbf{F}$ & 59 & 1975 & 5 & + & C, $\mathbf{L}$ & Alive & Ac Nec \\
\hline $\mathbf{R H}$ & $\mathbf{F}$ & 66 & 1976 & 15 & + & D & Alive & S/Ac \\
\hline $\mathbf{A L}$ & $\mathbf{F}$ & 64 & 1976 & 20 & + & $\mathbf{C}, \mathbf{N}$ & Died after 12 months & Ac Nec \\
\hline EY & $\mathbf{F}$ & 67 & 1978 & 15 & - & $\mathrm{C}, \mathbf{N}, \mathbf{F}$ & Died after 18 months & $\mathrm{Ac} \mathrm{Nec}$ \\
\hline EL & $\mathbf{F}$ & 67 & 1978 & 13 & - & C, $\mathbf{R}, \mathbf{F}$ & Alive & Ac Nec \\
\hline$\overline{N J}$ & $\mathbf{F}$ & 62 & 1979 & 12 & + & $\mathrm{C}, \mathbf{N}$ & Alive & Ac Nec \\
\hline WF & $\mathbf{M}$ & 38 & 1979 & $1 \cdot 5$ & + & C & Alive & Ac Nec \\
\hline CJ & $\mathbf{M}$ & 66 & 1979 & 20 & + & $\mathbf{C}, \mathbf{N}, \mathbf{H}$ & Alive & Leuco \\
\hline NL & $\mathbf{M}$ & 57 & 1979 & 0.5 & - & C & Alive & S/Ac \\
\hline GR & $\mathbf{M}$ & 62 & 1979 & 15 & + & $\mathbf{F}$ & Alive & $\mathrm{Chr}$ \\
\hline $\mathbf{W N}$ & $\mathbf{F}$ & 59 & 1980 & 30 & + & $\mathrm{C}, \mathrm{S}$ & Alive & S/Ac \\
\hline JR & $\mathbf{M}$ & 70 & 1980 & 7 & + & C & Alive & Ac Nec \\
\hline
\end{tabular}

$\begin{array}{lll}* \mathbf{C}=\text { cutaneous } & \mathbf{D}=\text { diarrhoea } & * * \text { Ac Nec = acute necrotising } \\ \mathbf{S}=\text { scleritis/Sjögren's } & \mathbf{H}=\text { cardiac } & \text { S/Ac }=\text { sub-acute necrotising } \\ \mathbf{N}=\text { neuropathy } & \mathbf{F}=\text { fibrosing alveolitis } & \text { Leuco = leucocytoclastic } \\ \mathbf{L}=\text { pseudolymphoma } & \mathbf{R}=\text { renal } & \mathbf{C h r} \text { = chronic "burnt out" }\end{array}$

extensive necrotising arteritis in the submucosal arteries. He has responded to corticosteroid and cytotoxic treatment and is well one year later. The third, a 66-year-old man, presented with an acute mononeuritis multiplex, malaise, weight loss, and an urticarial skin rash. He was Australia antigenpositive, and his rectal biopsy showed a typical necrotising arteritis. He has recently started treatment with corticosteroids and appears to be responding well.

\section{(c) Overlap syndromes-3 cases}

The first of these was a 41-year-old man with a short history of fever, weight loss, and cutaneous ulcers. Serology and a renal biopsy confirmed a diagnosis of systemic lupus erythematosus (SLE). He developed a vasculitic skin rash with disseminated intravascular coagulation and a rectal biopsy showed a sub-acute vasculitis. Death occurred due to acute renal failure and adrenal infarction.

The remaining two women patients had clinical features of both RA and SLE. One patient, aged 55, with nailfold vasculitis, peripheral arthritis and Raynaud's syndrome developed fibrosing alveolitis. Rectal biopsy showed a necrotising arteritis (Fig. 2). She has responded to treatment and the current diagnosis is mixed connective tissue disease. The other patient, aged 74, had a chronic nodular vasculitis of the legs which preceded the development of a peripheral arthritis. Serology suggested SLE and the rectal biopsy on this patient also showed a necrotising arteritis. She failed to respond to treatment and died from concurrent sepsis.

\section{CONTROLS}

Two control groups were studied:

(a) Thirty-one rectal biopsies, originally taken to $\stackrel{\infty}{-}$ exclude amyloidosis in a series of patients with long 0 standing RA ( $>18$ yr duration) were reviewed. These were all recut as described earlier and no evidence of active or chronic vasculitis was found.

(b) Rectal biopsies were also taken from $15 \%$ patients with very active rheumatoid synovitis, but $\stackrel{2}{\Rightarrow}$ without clinical features of vasculitis, and only one $\stackrel{0}{3}$ showed histological evidence of vasculitis.

\section{COMPLICATIONS}

Many biopsies were taken in the outpatients depart-용 ment and local haemorrhage was only rarely trouble- some. Intestinal perforation was the only serious 3 . complication and occurred in two patients. In both $\delta$ cases the tissue was obtained via a sigmoidoscope. The biopsies were not full thickness and the perfora-o tions were most likely due to increased intra luminal pressure following insufflation. In one case theo perforation occurred at the rectosigmoid junction well above the biopsy site and in the other the anterior 0 rectal wall was inadvertently biopsied.

\section{Discussion}

The vasculitides may be seen as a spectrum of diseases with a group of conditions characterised by necrotising vasculitis at one end (such as PAN) and mainly granulomatous lesions at the other (such as RA) with other connective tissue diseases in the middle. ${ }^{7}$ In many patients overlapping clinical $\stackrel{\mathbb{Q}}{\mathrm{D}}$ 
features are common ${ }^{8}$ and it is important to obtain a tissue diagnosis.

Follow-up studies during life and also detailed necropsies are required if a greater understanding of the natural history of this difficult group of patients is to be achieved. This is especially important if the effect of different therapeutic regimens is to be assessed accurately.

A variety of tissues have been biopsied to look for histological evidence of vasculitis. The commonest site is skeletal muscle. Results of open muscle biopsies from patients with PAN are disappointing with positive findings in less than $40 \% .9$ In RA, Schmid ${ }^{10}$ found evidence of vasculitis in 13 of 19 patients with systemic rheumatoid disease (many with neuropathy) but also in four of 12 patients with uncomplicated arthritis. Eleven out of these 17 positive biopsies showed a necrotising vasculitis.

Sural nerves have been biopsied in patients with neuropathy complicating RA and are reported to show both sub-acute and necrotising vasculitis. ${ }^{11} 12$ However, this technique requires examination of an entire segment of the sural nerve. ${ }^{11}$ Both sural nerve and open muscle biopsies are surgical procedures causing discomfort and scarring and may be dangerous in patients with widespread cutaneous lesions.

Testicular biopsies have occasionally been used in cases of suspected PAN ${ }^{13}$ but this is obviously limited by problems including sex and patient antagonism.

Biopsies of recent cutaneous lesions are likely to give the highest frequency of positive results but interpretation is often difficult and correlation with systemic involvement is often poor. ${ }^{14}$

Renal biopsies have a definite morbidity and mortality. These should be reserved for patients with clinical evidence of renal involvement. In suspected PAN we have found confirmatory changes in at least $50 \%$.

We have found only two previous reports on the use of rectal biopsy in the diagnosis of vasculitis. The first, in 1968, was by Schneider and Robbins ${ }^{4}$ who described arteritis in rectal biopsies taken from six out of 36 patients. Five of these had RA while the other patient had a clinical diagnosis of "collagen disease." Twenty-two of the 36 patients had RA and of the five positive biopsies only one showed fibrinoid necrosis. The authors noted that those patients with arteritis had a more advanced and prolonged disease as well as a high incidence of nodules, hypertension, pericarditis and cardiovascular manifestations than the patients in the group with negative rectal biopsies. Our findings in a larger series support and amplify this original report. The second report in $1971^{5}$ was a short communication from Israel describing two cases of necrotising arteritis in rectal biopsies from patients with PAN. It is of interest that both these biopsies had been originally performed to exclude amyloidosis. We also originally obtained rectal biopsies from patients with RA with suspected amyloidosis and in a few found necrotising vasculitis in the submucosal arteries in the absence of amyloid. On enquiry these patients had clinical features of vasculitis, and we have therefore used this procedure to establish a histological diagnosis in all patients with suspected vasculitis. A positive biopsy in the absence of local visible disease may suggest systemic rather than localised vasculitis. This may explain why a high incidence of neuropathy, circulating immune complexes and mortality correlated with histological proof of vasculitis in rectal biopsies from patients with rheumatoid vasculitis. ${ }^{6}$

The timing of the biopsy is also important as was illustrated by patient (EL) who had four serial biopsies which showed transformation from necrotising vasculitis to sub-acute vasculitis in three months and to "burnt-out" vasculitis by 10 months. This revealed the natural history of the rectal vasculitis in this patient and illustrates the use of this biopsy site in serial studies.

Our results suggest that a positive biopsy correlated well with clinical evidence of systemic vasculitis. In only one of our 46 RA control series did we find an unexpected vasculitis and also only one of our 16 original RA patients $(\mathrm{RH})$ had no clinical features of vasculitis. It is of interest that this was the only positive biopsy in which the vasculitis was confined to veins.

It is worth repeating that our incidence of $34 \%$ positive rectal biopsies in RA vasculitis may be "falsely-low" due to inadequate tissue. This figure still compares favourably with those obtained from other biopsy sites and repeat biopsies might have increased our yield. We have not routinely undertaken rectal biopsies on all patients with suspected PAN, but of six recent cases, biopsies in two showed a necrotising vasculitis. Gastrointestinal involvement is common in PAN with a reported incidence of up to $70 \% 15$ and further work is clearly required to evaluate the use of rectal biopsy in this disease.

All three patients with overlap syndromes had features of SLE. It has been suggested that all manifestations of SLE are due to small vessel vasculitis. ${ }^{16}$ More rarely a diffuse systemic vasculitis similar to PAN is reported. ${ }^{17}$ The presence of vasculitis on rectal biopsy in these patients is not surprising.

We have seen necrotising vasculitis in renal biopsies from patients whose rectal biopsies taken within a few days of renal biopsy were negative. This suggests that rectal biopsy is not necessarily the most 
sensitive method for diagnosing systemic vasculitis, but that it is relativeiy specific.

It is worth stressing to the clinician the importance of obtaining tissue from the posterior wall of the rectum through a proctoscope to avoid the serious complication of intestinal perforation. Under these conditions rectal biopsy has the advantage over other biopsy sites of being painless, repeatable and safe.

It is worth stressing to the pathologist, when examining rectal, or any other biopsy tissue for evidence of vasculitis, the importance of taking close step sections through the entire biopsy and to stain some sections for elastic fibres. The focal nature of all types of vasculitis is one of the most enigmatic features of these diseases and we never cease to be amazed how, even with a small portion of rectal tissue, the first series of sections can be normal whereas an obvious necrotising vasculitis, often confined to one small artery, is revealed in the deeper sections.

We are grateful to the physicians of Southmead Hospital, Bristol and the Royal National Hospital for Rheumatic Diseases, Bath, for allowing us to study their patients. We also thank Mr B Amer for the photomicrographs and Mrs Carol Baker for secretarial assistance. DGI Scott was supported by a South Western Regional Health Authority research grant.

\section{References}

${ }^{1}$ Gafni J, Sohar E. Rectal biopsy for the diagnosis of amyloidosis. Am J Med Sci 1960;240:332-6.

${ }^{2}$ Arapakis G, Tribe CR. Amyloidosis in rheumatoid arthritis, investigated by means of rectal biopsy. Ann Rheum Dis 1963;22:256-62.

${ }^{3}$ Bacon PA, Tribe CR, Harrison P, McKenzie JC. Rheumatoid disease Amyloidosis and its treatment with penicillamine. Eur J Rheum Inflamm 1979;2:70-4.

${ }^{4}$ Schneider RE, Dobbins WO. Suction biopsy of the rectal mucosa for diagnosis of arteritis in rheumatoid arthritis and related diseases. Ann Intern Med 1968;68:561-8.

${ }^{5}$ Rosenman E, Levij IS. Rectal biopsy as a diagnostic aid in periarteritis nodosa. Isr J Med Sci 1971;7:1082-4.

${ }^{6}$ Scott DGI, Bacon PA, Tribe CR. Systemic rheumatoid vasculitis: A clinical and laboratory study of 50 cases. (in press).

? Alarcon-Segovia D, Brown AL. Classification and etiologic aspects of necrotising angiitides: an analytic approach to a confused subject with a critical review of the evidence of hypersensitivity in polyarteritis nodosa. Mayo Clin Proc 1964;39:205-22.

${ }^{8}$ Bywaters EGL. The Cheshire cat syndrome. Postgrad Med $J$ 1968;44:19-22.

${ }^{9}$ Maxeiner SR, McDonald JR, Kirklin JW. Muscle biopsy in the diagnosis of periarteritis nodosa. Surg Clin North Am 1952;32:1225-33.

${ }^{10}$ Schmid FR, Cooper NS, Ziff M, McEwan C. Arteritis in rheumatoid arthritis. Am J Med 1961 ;30:56-83.

${ }^{11}$ Conn DL, McDuffie SC, Dyck PJ. Immunopathologic study of sural nerves in rheumatoid arthritis. Arthritis Rheum 1972;15:135-43.

${ }^{12}$ Starz TW, Medsger TA, Eisenbeis $\mathrm{CH}$, Mitre BK, Rabin BS, Tolchin SF. Sural nerve biopsies in rheumatoid arthritis; Light microscopic and immunofluorescent findings in 13 patients. Arthritis Rheum 1978;21:823-4.

${ }^{13}$ Dahl EV, Baggenstoss AH, DeWeerd JH. Testicular lesions of periarteritis nodosa with special reference to diagnosis. Am J Med 1960;28:222-8.

${ }^{14}$ DeShazo RD, Levinson AI, Lawless JO, Weisbauma G. Systemic vasculitis with co-existent large and small vessel involvement: A classification dilemma. JAMA 1977;238:1940-2.

${ }^{15}$ Rose GA. The natural history of polyarteritis. $\mathrm{Br} \mathrm{Med} \mathrm{J}$ 1957;ii:1148-52.

${ }^{16}$ Maini RN, Glass DN, Scott JT. Aspects of autoimmunity. In: Turk $\mathbf{J}$, ed. Immunology of the rheumatic diseases. London: Edward Arnold, 1977:115.

17 Mintz G, Fraga A. Arteritis in systemic lupus erythematosus. Arch Intern Med 1965;116:55-66.

Requests for reprints to: Dr CR Tribe, Department of Pathology, Southmead General Hospital, Westbury-onTrym, Bristol BS10 5NB, England. 